The survey also shows that the community team, especially the community nurses, have good understanding of emergency, where all their referrals showed valid needs for requests. Possible medical or psychiatric emergencies should not deter professionals from resettlement programmes or community care. Most can be dealt with in community settings. A trained, experienced and harmonious community team, a well organised back-up service of generic

hospital beds and admission-assessment units for mentally handicapped people will deal with emergencies effectively.

\title{
Reference
}

Nolan, M. E., Radakrishnan, G. \& Lewis, J. (1992) Generic services for people with a mental handicap. Psychiatric Bulletin, 16, 212-213.

\section{A Nigerian psychiatric emergency service: factors associated with utilisation}

\author{
R. A. Adeniran, Registrar, North Wales Hospital, Denbigh, Clwyd LL16 5SS; and \\ O. A. Suuwola, Professor of Psychiatry, Neuropsychiatric Hospital \& WHO \\ Collaborating Centre for Research \& Training in Mental Health, Abeokuta, \\ Nigeria
}

The psychiatric emergency service is a major focal point of entry into the mental health system. Depending on the health care policy and other sociocultural factors, the pattern of attendance in a psychiatric emergency unit tends to differ from one country to another (Bassuk et al, 1983).

The psychiatric emergency service often reflects the ideology and provision of mental health services in a community, while the nature of the population utilising it reflects the psychiatric trends in that community. Various studies about the pattern of utilisation of psychiatric emergency services in many countries have shown that for a large number of patients, the psychiatric emergency unit is the source of primary care. There has been no such study in Nigeria and mental health is now part of the primary health care in the country. In planning and providing mental health care at the grass roots, there is a need to know the nature and extent of psychopathology in the population and the pattern of utilisation of existing services.

This study was conducted to identify the population that make use of a Nigerian psychiatric emergency unit and the factors associated with this. Since there is now a focus on mental health at the primary care level, it is hoped that our findings would supplement existing information to assist planning and service provision.

\section{The study}

The study was conducted in the assessment unit of the Neuropsychiatric Hospital, Aro, Abeokuta, Nigeria. It is Nigeria's foremost psychiatric hospital with 526 beds and no defined catchment area. The assessment unit has an open door policy. It serves as the first contact point for all patients coming to the hospital for the first time and provides a 24-hour service, including emergency services seven days of the week.

All consecutive patients seen at the assessment unit over a two-month period between April and June 1989 were included in the study. Data were collected on case histories, sociodemographic status, psychiatric and physical assessment. Psychiatric diagnoses were made according to the first two axes of the Diagnostic and Statistical Manual, 3rd Edition. For the purpose of this study, psychiatric emergencies were operationally defined as follows:

(a) all patients who presented after normal working hours

(b) all patients who presented on weekends and public holidays

(c) all patients who presented during normal working hours and had to be referred on the same day to the out-patient clinic. 


\section{Findings}

\section{Basic social data}

During the period of study, 330 patients were seen at the assessment unit. Of these, 174 fulfilled the criteria for psychiatric emergency as defined above. There were 90 men and 84 women. Of these, 38 were old patients and 136 were new. They were between 6 and 74 years of age, with a mean of $30.7 \pm 12.5$. The majority $(80 \%)$ were aged between 10 and 39 years. The men (mean age: $28.6 \pm 10.6)$ were significantly younger than the women (mean age: $33.1 \pm 13.9$; $\mathrm{t}=2.4, P<0.05)$. Ninety-four patients $(54 \%)$ were single, $29 \%$ were married, and the others were either separated, divorced or widowed. Males were significantly more likely to be single $(\mathrm{M}: \mathrm{F}=67.27$; $\chi^{2}=29.62 ; P<0.05$ ).

Nine of the men and 28 women had no formal education. Men were significantly more likely to have formal education $\left(\chi^{2}=12.77 ; P<0.05\right)$. Thirtyfour men were either unemployed or unskilled (messengers, labourers, etc) while 68 women belonged in this category, mostly housewives and petty traders. The men were significantly more skilled (technicians, professionals, etc) than women $\left(\chi^{2}=31.63 ; P<0.05\right)$.

\section{Events prior to presentation}

The majority of patients $(94.2 \%)$ came from within 100 kilometres of the hospital while $37.9 \%$ came from within 50 kilometres. One patient came from the Republic of Benin, which is a neighbouring West African country.

Delay in presentation was common, with $39 \%$ presenting within one month and $34.4 \%$ after one year of the onset of illness. Many (74.1\%) had received one or more forms of treatment, which included a traditional form of treatment $(73 \%)$ before presentation. Only nine of the old patients received treatment prior to presentation, while 120 new patients did. Old patients were significantly less likely to have received treatment $\left(\chi^{2}=61.22 ; P<0.05\right)$. Only 5.7\% were referred by a medical agency, $88.5 \%$ were brought by relatives, $2.9 \%$ came on their own, and $2.9 \%$ were brought by the police.

\section{Clinical data}

Two thirds $(66.6 \%)$ of the patients had functional psychoses and $5.8 \%$ had neurotic disorders. The commonest diagnosis was schizophrenia $(28.2 \%)$ and among patients with essentially non-psychiatric conditions $(12.1 \%)$, the commonest diagnosis was seizure disorder $(9.2 \%)$. All the $21(12.1 \%)$ patients with substance abuse were men and six of eight patients with a major form of depressive illness were women.

Forty-one men and 19 women presented after 12 months of onset of illness. At a significant level, women tended to present earlier than men $\left(\chi^{2}=9.13\right.$; $P<0.05)$; those who never had any form of treatment prior to presentation tended to present earlier than those who did $\left(\chi^{2}=16.10 ; P<0.05\right)$, and old patients tended to present earlier than new ones $\left(\chi^{2}=16.76\right.$; $P<0.05)$.

\section{Comment}

In this study the majority of the patients were young adults and were just as likely to be male as female. This is similar to the findings of a study of a psychiatric emergency service in India (Kelkar et al, 1982). However, in a later study in India, Jee et al (1988) found that men outnumbered women. An excess of men among emergency psychiatric patients was also found in studies from the United Kingdom and United States of America (Bassuk et al, 1983; Lim, 1983). Lim (1983) concluded that an overrepresentation of males in these settings was due to demographic pattern in the locality. However, Jee et al (1988) suggested that, concerning their findings in India, the explanation is sociocultural; and that mental illness in the case of females might not be given priority for urgent treatment. The demographic pattern of our patients is in keeping with previous findings of psychiatric patients in Africa (Makanjuola, 1985). Our patients are a cross-section of the people in the community. We found that men tended to present later than women and men were more likely to be single, educated and skilled. Because most patients were brought by spouses or relations, the single man is less likely to present early, and as the breadwinner, the man would tend to hold on to his job for as long as possible until the illness became incapacitating.

Most patients came from within 100 kilometres of the hospital, and although not statistically significant, we found that patients from the immediate environment tended to present earlier. Studies have shown that accessibility of mental health care facilities is a major determinant of the use of the services. The long delay observed in a high proportion of our patients is in keeping with previous findings of Nigerian psychiatric patients seeking orthodox care for the first time (Makanjuola, 1985). Most of the patients received treatment from traditional healers prior to presentation. Traditional healers are known to look after a considerable proportion of the mentally ill in Nigeria; their role especially in informal psychotherapy has long been recognised. The tendency over the years has been to resort to orthodox psychiatric care when a traditional form of treatment has failed. This is due largely to the cultural concepts of the aetiology and management of psychiatric disorders. We found that patients who did not consult traditional healers tended to present earlier than those who did, and old patients tended to present 
earlier than new ones. Having had previous experience of orthodox care, we found that old patients were less likely than new ones to have received a traditional form of treatment before presentation. Thus there seems to be some connection between seeing a traditional healer and delay in presentation.

The clinical profile of our patients is similar to the findings of Makanjuola (1985) in his study of new Nigerian psychiatric patients. The patients presented essentially owing to the severity of their clinical condition.

Our findings would suggest the need for more health education to aid early recognition of mental illness and prompt therapeutic intervention. The clinical profile gives an indication of the nature of the morbidity of patients seeking emergency psychiatric care and it could inform staffing provision and training at the primary care level.

Although this hospital operates an open door policy, it is a tertiary institution and for psychiatric patients only; it would therefore be desirable to replicate the study in general and teaching hospitals to paint a more comprehensive picture.

\section{Acknowledgement}

We wish to thank Professor M. O. Akindele for his support.

\section{References}

Bassuk, E. L., Winter, R. \& Apsler, R. (1983) Crosscultural comparison of British and American psychiatric emergencies. American Journal of Psychiatry, 140, $180-184$.

JeE, A., Mohan, D. \& Wig, N. N. (1988) Determinants of emergency room visits. International Journal of Social Psychiatry, 34, 25-30.

Kelkar, D. K., Chaturvedi, S. K. \& Malhorta, S. (1982) A study of emergency psychiatric referrals in a teaching general hospital. Indian Journal of Psychiatry, 24, 366-369.

LiM, M. H. (1983) A psychiatric emergency clinic: a study of attendances over six months. British Journal of Psychiatry, 143, 460-466.

MaKanjuola, R. O. A. (1985) Clinical and sociocultural parameters in Nigerian psychiatric patients. Acta Psychiatrica Scandinavica, 72, 512-521.

\section{Delusions and Hallucinations in Old Age}

\section{Edited by CORNELIUS KATONA and RAYMOND LEVY}

The fascinating but somewhat neglected topic of the alteration in the sense of reality in the elderly mentally ill is tackled by contributors from seven European countries. This book spans the field from the historical and conceptual issues to the latest findings in neuroimaging without overlooking basic phenomenology and treatment. It brings together new clinical data and information hitherto widely scattered in relatively inaccessible publications to provide a comprehensive overview of the topic.

GASKELL Royal College of Psychiatrists

256pp., ISBN 090224147 8, Price $£ 12.50$ 